\title{
Huge right ventricular mass lesion associated with genital malignant tumor: a case report
}

\author{
Masaya Higashi', Akihiko Hodatsu' ${ }^{1}$, Katsuharu Uchiyama' ${ }^{1}$, Hayato Tada², Mika Mori ${ }^{2}$, Miho Ohira², \\ Kenshi Hayashi ${ }^{2}$ and Masa-aki Kawashiri ${ }^{2}$
}

\begin{abstract}
Background: Primary heart tumors are rare, whereas metastatic heart tumors occur more frequently.

Case presentation: We report a case of a 75-year-old Japanese woman who had metastatic heart tumors of the right ventricle. Although she initially received antibiotic therapy following a diagnosis of pneumonia and pleuritis, her symptoms worsened, and she developed dyspnea and bilateral lower limb edema. Echocardiography showed a huge mass lesion occupying the entire right ventricle. Because the patient's tumor markers were elevated, we used computed tomography to search for the primary lesion, which was located in the vagina or the uterus. Histology demonstrated the presence of basaloid squamous cell carcinoma in the vaginal tissue. Chemotherapy with paclitaxel and carboplatin was initiated.
\end{abstract}

Conclusions: These data suggest that the tumor in the right ventricle metastasized from the genital organs.

Keywords: Cardiac tumor, Metastatic heart tumor, Congestive heart failure

\section{Background}

Primary heart tumors are rare, appearing in $0.02 \%$ of autopsies [1]. Metastatic heart tumors occur more frequently, and their probability of occurrence ranges from $2.3 \%$ to $18.3 \%$ [2]. In general, metastatic heart tumors are asymptomatic. Although these metastases rarely grow in the heart cavity, they often lead to lethal complications, such as embolism and obstruction of heart cavity inflow or outflow. We report a case of a patient with multiple metastases from the genital organs, including the right ventricle.

\section{Case presentation}

A 75-year-old Japanese woman was admitted to our clinic because of dyspnea associated with bilateral lower limb edema. She was well until 8 weeks before admission, when she began to complain of back pain and cough. Although a local doctor gave her antibiotics after a diagnosis of pneumonia, her symptoms worsened. One

\footnotetext{
* Correspondence: ht240z@sa3.so-net.ne.jp

${ }^{2}$ Department of Cardiovascular and Internal Medicine, Kanazawa University Graduate School of Medicine, 13-1 Takara-machi, Kanazawa 920-8641, Japan Full list of author information is available at the end of the article
}

week later, she consulted our clinic, where different antibiotics were prescribed to relieve her symptoms. However, she complained of dyspnea with bilateral lower limb edema, which suggested congestive heart failure.

The patient's oxygen saturation on admission was $90 \%$, although her blood pressure $(124 / 82 \mathrm{mmHg})$ and heart rate ( 95 beats/minute) were stable. Coarse crackles were audible in the lung field. Significant bilateral lower limb edema was observed. Blood analysis revealed that the patient had a C-reactive protein level of $7.53 \mathrm{mg} / \mathrm{dl}$ and a brain-type natriuretic peptide level of $668.5 \mathrm{pg} / \mathrm{ml}$. Although the patient's electrocardiogram (ECG) did not produce any significant findings, her chest $\mathrm{x}$-ray showed an enlarged heart associated with infiltration of both lung fields, particularly in the lower right area (Fig. 1).

When we examined the patient's echocardiogram, we saw a huge mass occupying the entire right ventricle. However, there was no mass lesion in the right atrium, suggesting the possible occurrence of the original tumor in the right ventricle (Fig. 2). Owing to obstruction of the right ventricle, the calculated right ventricular pressure was $49.5 \mathrm{mmHg}$. The right ventricular mass was confirmed by cardiac magnetic resonance imaging, 


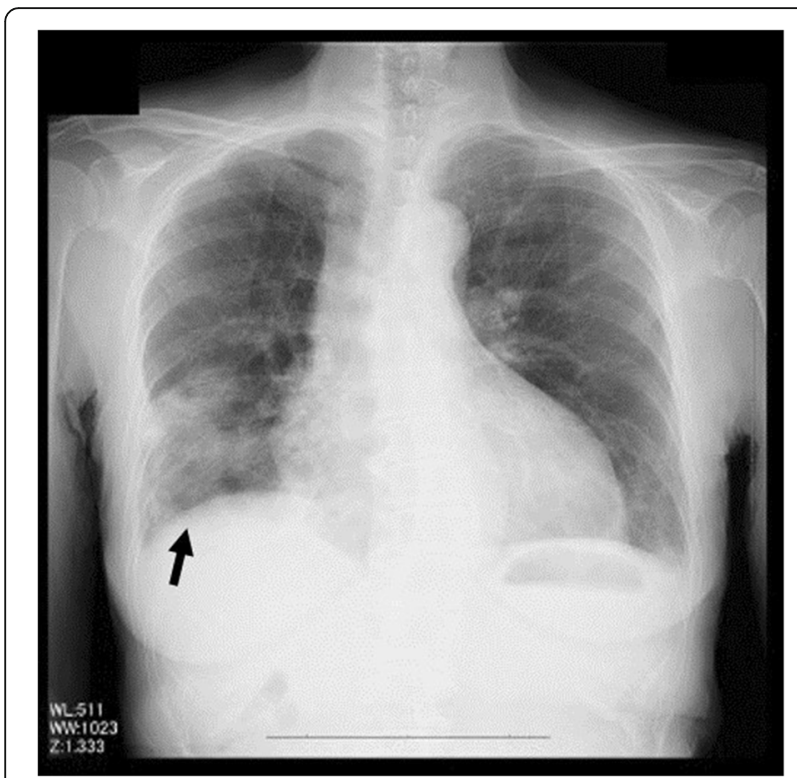

Fig. 1 Chest $x$-ray showing enlarged heart associated with infiltration of both lung fields, particularly in the lower right area (black arrow) which showed a mass occupying the entire right ventricle (Fig. 3). Importantly, the patient's cancer antigen 125 (CA 125) and soluble interleukin 2 receptor (sIL-2R) levels were markedly elevated at $135.6 \mathrm{U} / \mathrm{ml}$ and $672 \mathrm{U} / \mathrm{ml}$, respectively.

Because of the elevation of tumor markers, such as CA 125 and sIL-2R, we carefully searched for malignant lesions. In addition to pulmonary embolization, there were several metastatic lesions in the lung field, pleura, inferior vena cava, lymph nodes, and kidney (Fig. 4). Importantly, the original tumor was located in the uterus and vagina, where it occupied the entire space (Fig. 4). Histology demonstrated basaloid squamous cell carcinoma in the vaginal tissue (Fig. 5), and chemotherapy with paclitaxel $(120 \mathrm{mg}$ ) and carboplatin (340 mg) according to the protocol for cancer of the uterine cervix was initiated, although the effectiveness of chemotherapy on cardiac metastasis is unclear.

\section{Discussion}

Most cases of cardiac metastatic tumor are asymptomatic until the tumor obstructs the heart chamber. In that situation, systemic chemotherapy has priority over resection of the tumor because surgical resection is indicated

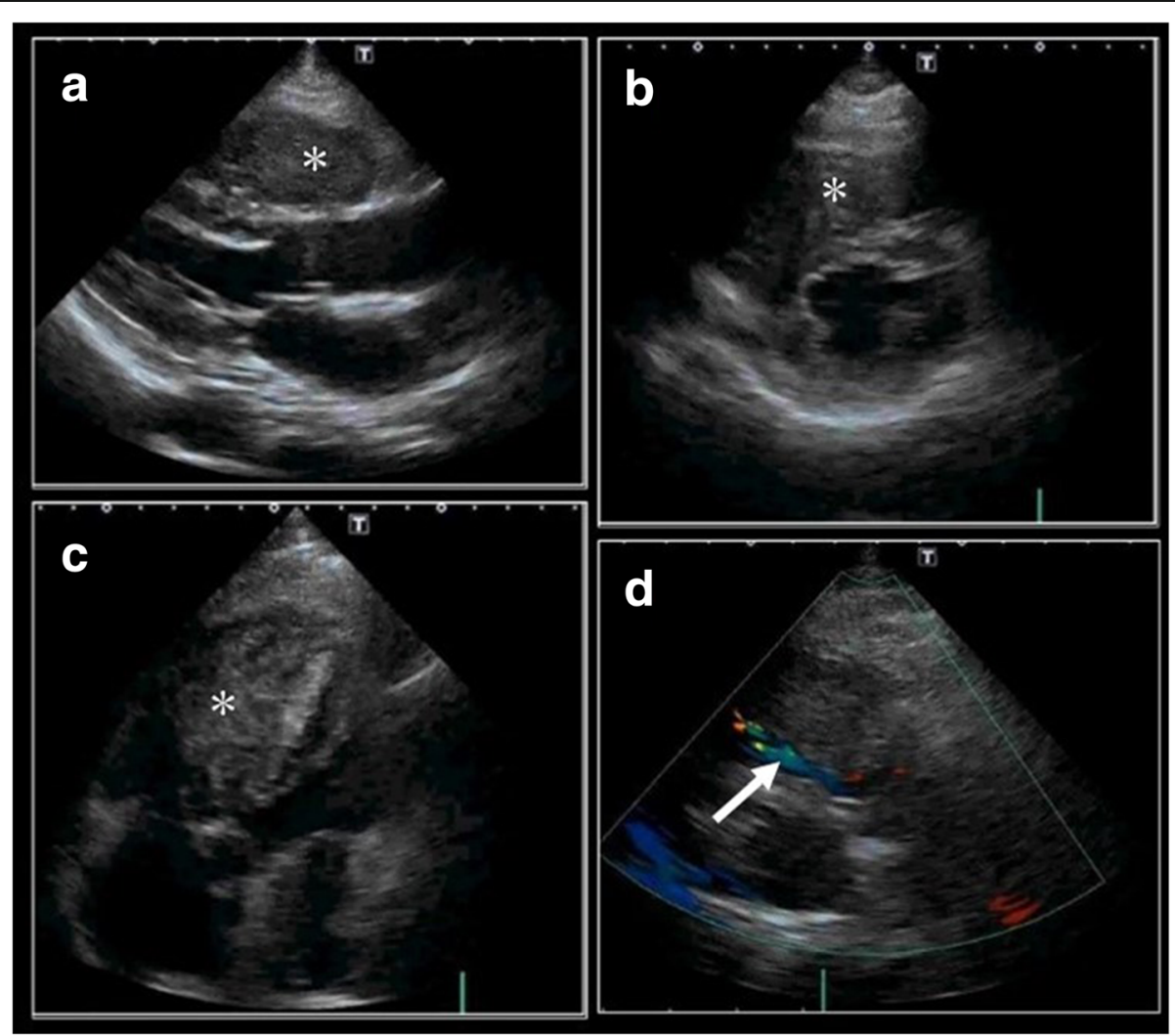

Fig. 2 Echocardiograms. a-c Echocardiograms revealing a huge mass occupying the right ventricle $\left(^{*}\right)$. There were no masses in the right atrium. The patient's right ventricular pressure was elevated, and the interventricular septum was flattened. $\mathbf{d}$ Color Doppler echocardiogram showing a disturbance in right ventricular outflow (white arrow) 


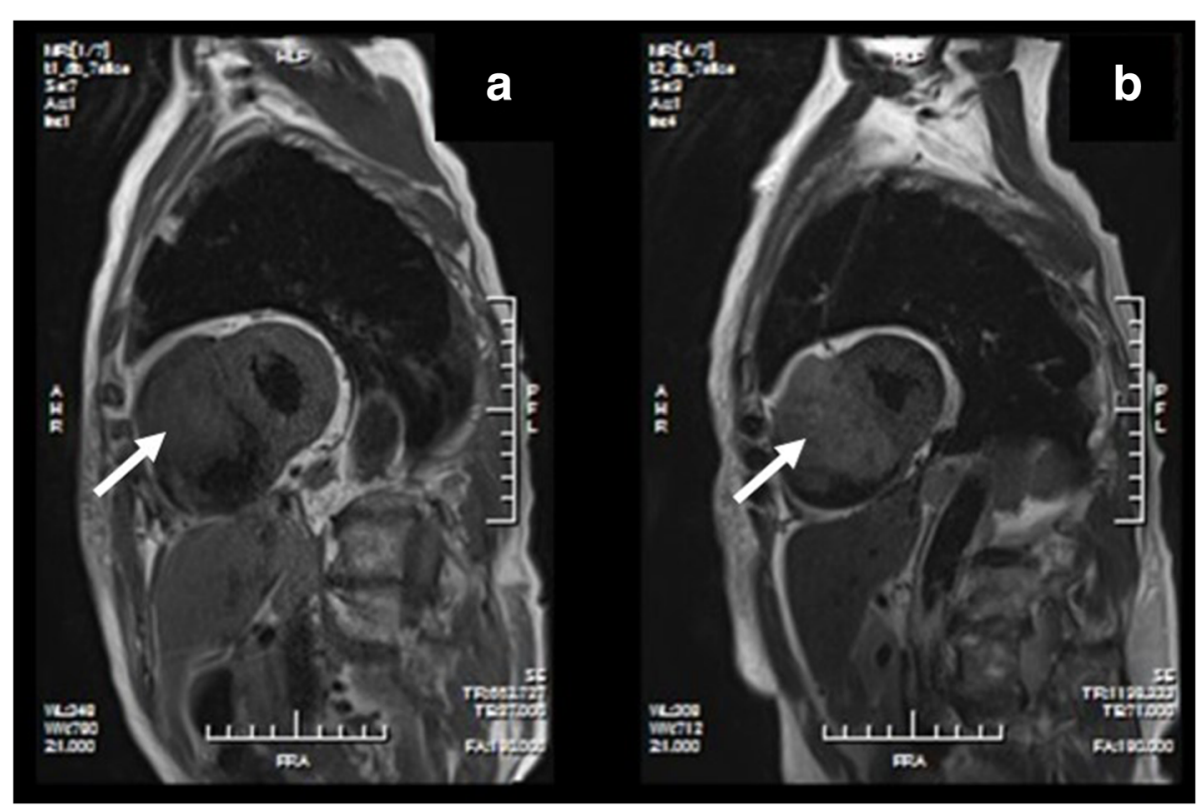

Fig. 3 Cardiac magnetic resonance imaging studies. $\mathbf{a}$ and $\mathbf{b}$ The presence of the tumor was confirmed by cardiac magnetic resonance imaging, which showed a mass occupying all the space in the right ventricle. The tumor and interventricular septum were poorly marginated. The arrows indicate tumors

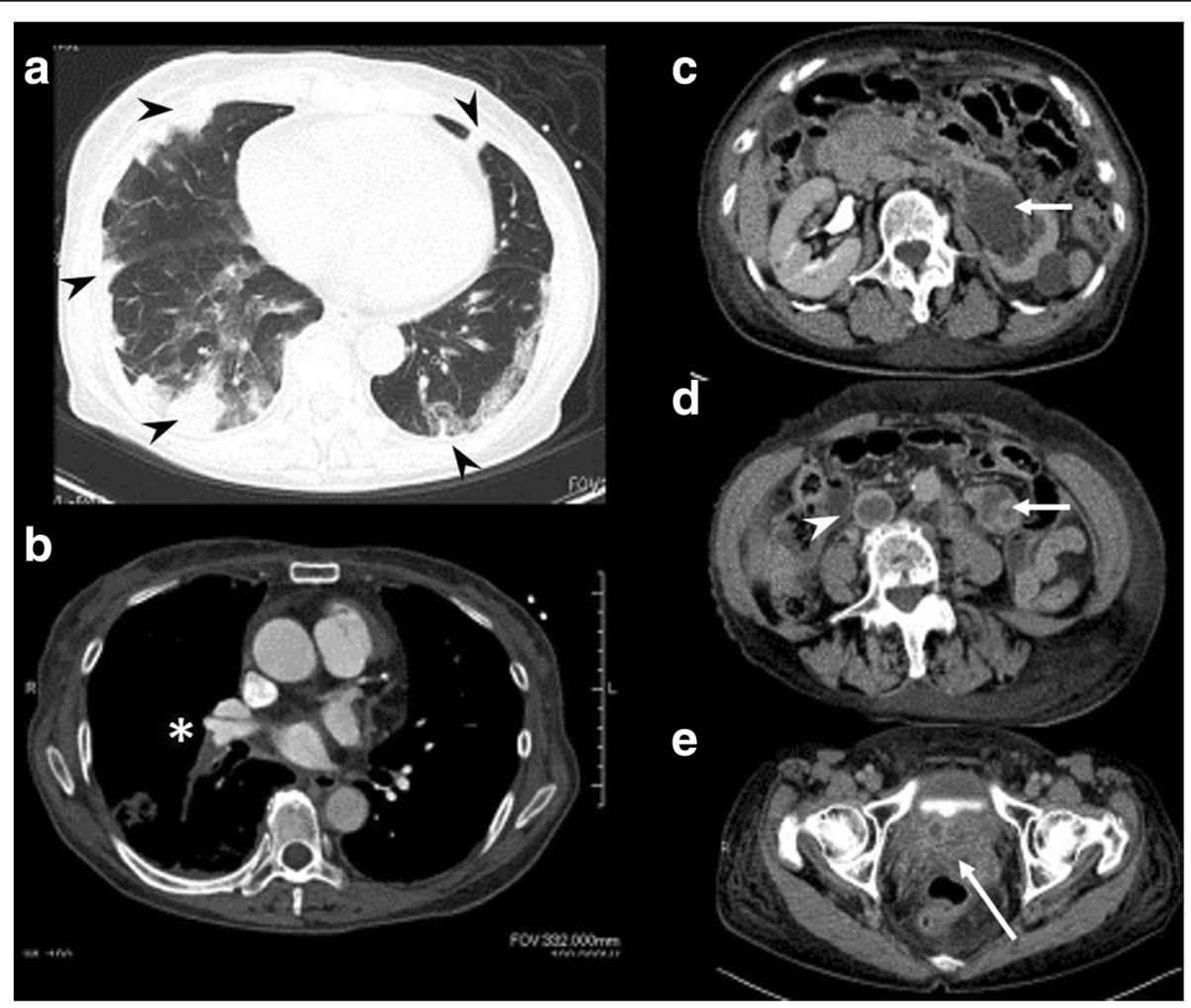

Fig. 4 Whole-body computed tomographic images showing several metastatic lesions. The arrowheads and asterisk indicate tumors. a Multiple nodular and infiltrative shadows were seen mainly in the peripheral lung field. $\mathbf{b}$ Contrast-enhanced computed tomography revealed tumor emboli in the right pulmonary artery. $\mathbf{c}$, $\mathbf{d}$ Left hydronephrosis indicates involvement of the lymph node near the left urinary duct. There were tumor thrombi in the inferior vena cava leading to the bilateral common iliac vein. e The uterus was completely occupied by the tumor 


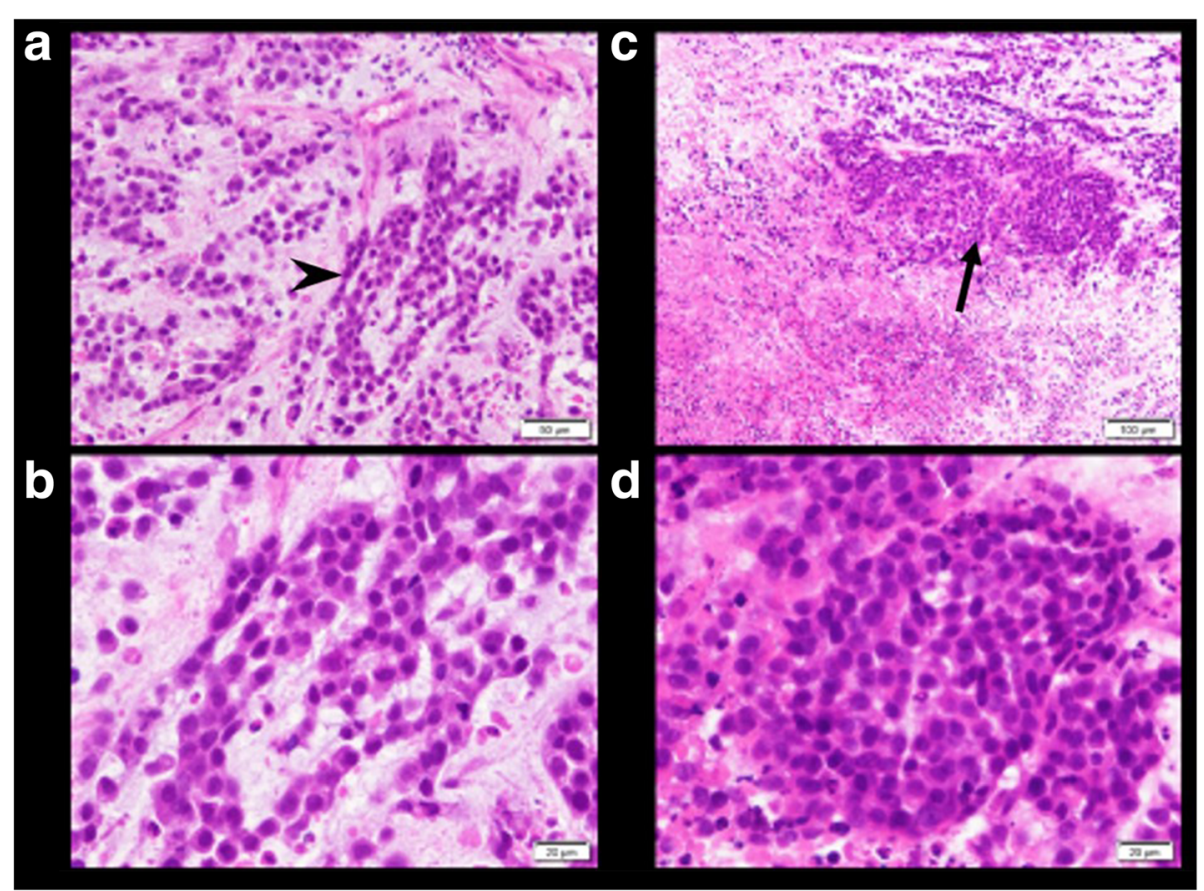

Fig. 5 Histological studies showing that large numbers of small basaloid cells (arrowhead) had invaded and displayed cordlike (a, b) or alveolar structures $(\mathbf{c}, \mathbf{d})$. The arrows indicate tumors

only for exceptional cases [3]. If complete resection fails, postoperative mortality is high [4].

Basaloid squamous cell carcinoma is a rare and highly aggressive variant of squamous cell carcinoma [5]. The most commonly involved sites are the larynx, hypopharynx, tonsils, and base of the tongue, not the heart [6]. In our patient, the squamous cell carcinoma antigen was not elevated, although it is a variant of squamous cell carcinoma [7], as shown in other cases $[8,9]$. Accordingly, in the case of our patient, it was difficult to diagnose the primary lesion on the basis of blood markers.

However, most tumors in the right side of the heart are metastatic malignant tumors [10], although some primary cardiac tumors have been reported [11]. Our patient initially developed respiratory problems that were followed by congestive heart failure. Clinically, cardiac metastasis usually remains asymptomatic. However, echocardiography should be performed as soon as symptoms of heart failure, angina pectoris, embolism, or rhythm disturbances develop; if a new heart murmur becomes audible; or if heart size is increased on a chest $\mathrm{x}$-ray. Alternatively, additional information may be obtained by computed tomography or magnetic resonance imaging [12].

\section{Conclusions}

We suggest that clinicians carefully examine the heart in patients with malignant tumors of the genital organs.

\section{Acknowledgements}

We appreciate Professor Masakazu Yamagishi for his assistance in revising the manuscript.

Funding

No financial support was received for this case report.

Availability of data and materials

All data generated or analyzed during this study are included in this published article.

\section{Authors' contributions}

All authors drafted the manuscript. All authors were involved in the care of the patient. All authors read and approved the final manuscript.

\section{Ethics approval and consent to participate}

The publication of this case report was approved by the clinical research ethics committees of Keijyu General Hospital.

\section{Consent for publication}

Written informed consent was obtained from the patient for publication of this case report and any accompanying images. A copy of written consent is available for review by the Editor-in-Chief of this journal.

\section{Competing interests}

The authors declare that they have no competing interests.

\section{Publisher's Note}

Springer Nature remains neutral with regard to jurisdictional claims in published maps and institutional affiliations.

\section{Author details}

${ }^{1}$ Division of Cardiology, Keiju General Hospital, Nanao, Japan. ${ }^{2}$ Department of Cardiovascular and Internal Medicine, Kanazawa University Graduate School of Medicine, 13-1 Takara-machi, Kanazawa 920-8641, Japan. 
Received: 19 July 2017 Accepted: 28 August 2017

Published online: 03 October 2017

\section{References}

1. Reynen K. Frequency of primary tumors of the heart. Am J Cardiol. 1996;77:107.

2. Bussani R, De-Giorgio F, Abbate A, Silvestri F. Cardiac metastases. J Clin Pathol. 2007:60:27-34.

3. Gibbs P, Cebon JS, Calafiore P, Robinson WA. Cardiac metastases from malignant melanoma. Cancer. 1999;85:78-84.

4. Poole GV, Meredith JW, Breyer RH, Mills SA. Surgical implications in malignant cardiac disease. Ann Thorac Surg. 1983;36:484-91.

5. Martínez-Girón R, Martínez-Torre S, Mosquera-Martínez AJ. Basaloid squamous cell carcinoma of the uterine cervix: cytological and histological features. Diagn Cytopathol. 2015;43:993-5.

6. Vasudev P, Boutross-Tadross O, Radhi J. Basaloid squamous cell carcinoma: two case reports. Cases J. 2009;2:9351.

7. Gadducci A, Tana R, Cosio S, Genazzani AR. The serum assay of tumour markers in the prognostic evaluation, treatment monitoring and follow-up of patients with cervical cancer: a review of the literature. Crit Rev Oncol Hematol. 2008:66:10-20.

8. Kawaguchi A, Shibata J, Naito H, Endo Y, Kodama M. One case of basaloid carcinoma of the esophagus [in Japanese]. Nihon Shokaki Geka Gakkai Zasshi. 1994;27:892-6.

9. Maruyama T, Endo M, Hirayama N, Murakami K, Matsubara H, Shioda K. A resected case of metastasis to the small intestine from esophageal basaloid cell carcinoma presented with small bowel obstruction. J Japan Surg Assoc. 2011;72:333-8

10. Yuda S, Nakatani S, Yutani C, Yamagishi M, Kitamura S, Miyatake K. Trends in the clinical and morphological characteristics of cardiac myxoma: 20-year experience of a single tertiary referral center in Japan. Circ J. 2002;66:1008-13.

11. Yamagishi M, Bando K, Furuichi S, Ishibashi-Ueda H, Yutani C, Miyatake K. Images in cardiovascular medicine: primary cardiac osteosarcoma in right ventricular outflow tract. Circulation. 2000:101:2220-1.

12. Reynen K, Köckeritz U, Strasser RH. Metastases to the heart. Ann Oncol. 2004;15:375-81.

\section{Submit your next manuscript to BioMed Central} and we will help you at every step:

- We accept pre-submission inquiries

- Our selector tool helps you to find the most relevant journal

- We provide round the clock customer support

- Convenient online submission

- Thorough peer review

- Inclusion in PubMed and all major indexing services

- Maximum visibility for your research

Submit your manuscript at www.biomedcentral.com/submit 